\title{
Magnetic force microscopy of YLaFeO films implanted by high dose of nitrogen ions
}

\author{
I.M. Fodchuk ${ }^{1}$, I.I. Gutsuliak ${ }^{1}$, R.A. Zaplitniy ${ }^{1}$, S.V. Balovsyak ${ }^{1}$, I.P. Yaremiy ${ }^{2}$, O.Yu. Bonchyk ${ }^{3}$, \\ G.V. Savitskiy ${ }^{3}$, I.M. Syvorotka ${ }^{4}$, P.M. Lytvyn ${ }^{5}$ \\ ${ }^{l}$ Yuriy Fedkovych Chernivtsi National University, \\ 2, Kotsiubinskyi str., 58012 Chernivtsi, Ukraine \\ ${ }^{2} V$. Stefanyk Prykarpatskyi National University, \\ 57, Shevchenko str. 76025 Ivano-Frankivsk, Ukraine \\ ${ }^{3}$ Institute for Applied Problems of Mechanics and Mathematics, NAS of Ukraine, \\ 3-b, Naukova str. 79601 Lviv, Ukraine \\ ${ }^{4}$ Scientific Research Company "Carat”, 202, Stryiska str., 79031 Lviv, Ukraine \\ ${ }^{5}$ V. Lashkaryov Institute of Semiconductor Physics, NAS of Ukraine, \\ 41, prosp. Nauky, 03028 Kyiv, Ukraine
}

\begin{abstract}
The scattering field gradient maps of surface layer magnetic domains in $\mathrm{Y}_{2.95} \mathrm{La}_{0.05} \mathrm{Fe}_{5} \mathrm{O}_{12}$ iron-yttrium garnet modified by high-dose ion implantation with nitrogen ions $\mathrm{N}^{+}$were obtained by the method of magnetic force microscopy. It was found that improving the magnetic properties of thin films, which includes reducing the observed magnetic losses after high-dose implantation, is accompanied by essential ordering of magnetic domains on the surface of the implanted films. There is a direct dependence of the magnetic properties on the dose of implanted atoms, accompanied by a significant dispersion and amorphization of surface layer and formation of a clear magnetic structure.
\end{abstract}

Keywords: iron-yttrium garnet, ferromagnetic resonance, epitaxial films, high-dose ion implantation, magnetic force microscopy.

Manuscript received 05.06.13; revised version received 07.08.13; accepted for publication 19.09.13; published online 30.09.13.

\section{Introduction}

Epitaxial yttrium-iron garnet (YIG) films have a unique set of structural and magnetic properties, which enables their widespread use as active medium of electronic devices. The study of these structures lasts several decades, they find their application as microwave technology devices, planar waveguide structures and lasers, magneto-optical devices and visual magnetometer sensors, etc. [1-3]. Performances of these structures are determined by properties of the surface layer of functional films with the thickness less than one micrometer, which allows its modification by postgrowth processing. In particular, the use of high-dose implantation method opens the possibility to create local areas with predetermined specific physical properties in ferrite-garnet films (FGF), which is of practical interest for magnetomicroelectronics and integrated magnetooptics because these conditions are difficult or even impossible to obtain in other magnetic structures.

Despite many performed versatile investigations of YIG structures, there is still a lot of non-ascertained questions in the process of creation of ionic defects in the films, the influence of the implantation mode on parameters of magnetic and crystalline microstructures, the course of radiation damage recovery process. Investigation of the distribution nature of magnetic domains and micromagnetic parameters along the film thickness as well as magnetic microstructure transformation and changes in the size and concentration 
of structural defects under the influence of high-dose implantation will help to develop mechanisms providing targetted modification of their properties.

\section{Objects of researches}

Epitaxial ferrite-garnet films (EFGF) of nominal composition $\mathrm{Y}_{3-x} \mathrm{La}_{x} \mathrm{Fe}_{5} \mathrm{O}_{12}$ were grown in SRC "Carat" (Lviv, Ukraine) by isothermal liquid-phase epitaxy from supercooled solution of garnet-creating components $\left(\mathrm{La}_{2} \mathrm{O}_{3}, \mathrm{Y}_{2} \mathrm{O}_{3}\right.$ and $\left.\mathrm{Fe}_{2} \mathrm{O}_{3}\right)$ in fusion of solvent on a horizontal rotating substrate [4]. Nonmagnetic crystals $\mathrm{Gd}_{3} \mathrm{Ga}_{5} \mathrm{O}_{12}$ with the crystal orientation of the input surface (111) were chosen as substrates. The basis of the solvent was eutectic composition $\mathrm{PbO}+15.6 \mathrm{~mol} \% \mathrm{~B}_{2} \mathrm{O}_{3}$. The growing process was carried out in the temperature range $940 \ldots 950{ }^{\circ} \mathrm{C}$ with the film growth rate $0.35 \mu \mathrm{m} / \mathrm{min}$. During the growth, the substrate revolved around its axis at the speed 60 to $90 \mathrm{rev} . / \mathrm{min}$. $\mathrm{La}^{3+}$ ions, which have larger ionic radius as compared with that of $\mathrm{Y}^{3+}$ ions, were introduced into the film to reduce the difference in lattice parameters of the film and the substrate.

Two series of epitaxial films with thicknesses $21.9 \mu \mathrm{m}$ (sample №1) and $76.4 \mu \mathrm{m}$ (sample №2) were selected for researches. Magnetic properties of the films were significantly changed after high-dose implantation with nitrogen ions, which should be investigated. Energy of ion implantation was $E=50 \mathrm{keV}$, the doses for films with the thickness $21.9 \mu \mathrm{m}$ were $D_{1}=0.5 \cdot 10^{18} \mathrm{ion} / \mathrm{cm}^{2}$ (sample №1a), $D_{3}=5 \cdot 10^{18}$ ion $/ \mathrm{cm}^{2}$ (sample №1b), and with the thickness $76.4 \mu \mathrm{m} \quad D_{2}=1.5 \cdot 10^{18} \mathrm{ion} / \mathrm{cm}^{2}$ (sample №2a).

\section{Results and discussion}

\subsection{FMR data}

The parameters of epitaxial garnet films, namely: saturation magnetization $\left(4 \pi M_{s}\right)$, ferromagnetic resonance (FMR) line width $2 \Delta H$, anisotropy field, depend on the distribution of cations inside the sublattices, the presence of oxygen vacancies, divalent iron ions, and mechanical stress $[5,6]$. The set of grown films demonstrate some changes in physical properties from film to film due to depletion of solvent even with fully repeated technological conditions of LPE growth such as the growth temperature, degree of supercooling of the melt solvent, substrate revolution speed, and so on [7]. Heat treatment in different environments and chemical etching of surface of epitaxial structures are used to optimize magnetic and other physical properties of ferrite-garnet layers.

The FMR line width determines electromagnetic losses in microwave devices. Decrease in the parameter $2 \Delta H$ leads to decrease of electromagnetic losses $[5,6,8]$. Quality of ferrite-garnet films is deteriorated by defects in the crystal structure, presence of impurity ions and oxygen vacancies, heterogeneity in the thickness and chemical composition of a studied area. All these factors lead to expansion of the FMR line and growth of electromagnetic losses.

The width of ferromagnetic resonance line was measured at FMR spectrometer AAZHS.468213.002 (SRC "Carat", Lviv) using the method of local excitation of resonance absorption ("magnetic hole" method) at a frequency of $3.1 \mathrm{GHz}$. The method consists in the fact that the conditions of ferromagnetic resonance are created using hole-like profile of constant magnetic field formed by a hole in one of the poles of electromagnet with epitaxial film in that hole. An important advantage of this method is the ability to locally measure the FMR line width in full-size EFGF structures (up to 3 inches $(76.2 \mathrm{~mm})$ in diameter) without their destruction, thus allowing us to provide rapid control of electromagnetic losses of epitaxial films for their applications in microwave devices in terms of their production. Parameters of the FMR line width are summarized in Table.

After high-dose implantation, there observed significant narrowing the FMR line width: for the first film by more than twice, for the second - by $18 \%$. This narrowing after implantation with nitrogen is very important when using films as elements of microwave devices [9].

\subsection{Atomic force microscopy}

The surface of the films was investigated using atomic force microscopy (AFM). The tapping mode of AFM measurements, which provides high sensitivity and allows to use high-resolution probes with a small radius of tip (about $5 \ldots 10 \mathrm{~nm}$ ), was used. Typical images of surfaces for the films of the sets №1 and №2 are shown in Fig. 1. Thin films (set №1) in the initial condition are characterized by the roughness $0.5 \mathrm{~nm}$ (over $50 \times 50 \mu \mathrm{m}^{2}$ area). Slight surface roughnesses of these films are distributed with a characteristic spatial period of $6.3 \mu \mathrm{m}$ according to the data of Fourier analysis (see the inset in Fig. 1a) [10]. The surfaces of thick films (set №2) are more developed (Fig. 1b). Continuous lace of ledges and hollows has a characteristic spatial period about $12 \mu \mathrm{m}$ and at the same time shows a tendency to create longrange order without presence of specific directions on the surface. Two-dimensional Fourier spectra contain characteristic amplitude oscillations. The roughness of the films is about $10 \mathrm{~nm}$ (over $70 \times 70 \mu \mathrm{m}^{2}$ area).

Table. Characteristics of the studied films.

\begin{tabular}{|c|c|c|c|c|c|c|}
\hline \multirow{2}{*}{ 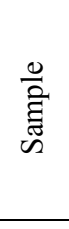 } & \multirow{2}{*}{ 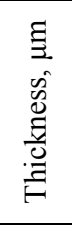 } & \multirow{2}{*}{ 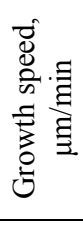 } & \multirow{2}{*}{ 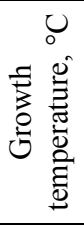 } & \multirow{2}{*}{$\begin{array}{c}\text { Molar } \\
\text { ratio } \\
\mathrm{Y}_{2} \mathrm{O}_{3} \\
\mathrm{La}_{2} \mathrm{O}_{3} \\
\text { in } \\
\text { fusion }\end{array}$} & \multicolumn{2}{|c|}{$\begin{array}{l}\text { FMR line width } \\
\qquad 2 \Delta H\end{array}$} \\
\hline & & & & & $\begin{array}{c}\text { non- } \\
\text { implanted }\end{array}$ & $\begin{array}{l}\text { im- } \\
\text { planted }\end{array}$ \\
\hline №2a & 76.4 & 0.35 & 950 & 10 & 1.27 & 1.08 \\
\hline №1b & 21.9 & 0.37 & 942 & 19 & 2.6 & 1.1 \\
\hline
\end{tabular}



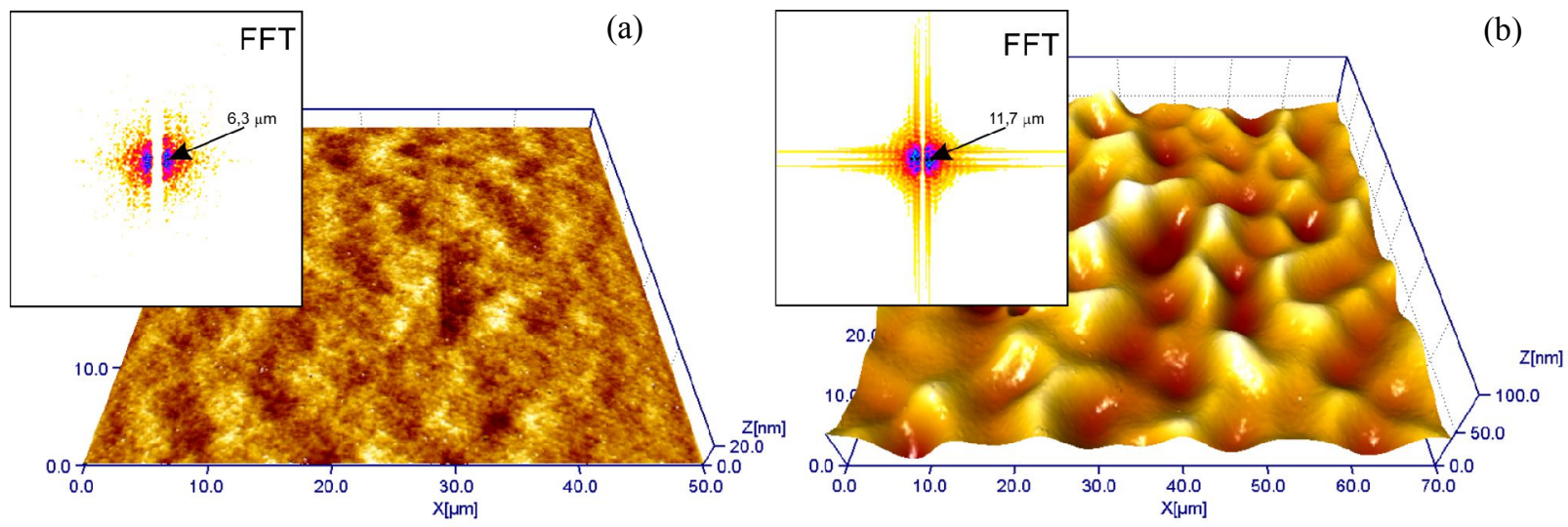

Fig. 1. AFM images of the surface areas of №1 (a) and №2 (b) films. The inset shows the data of Fourier analysis of characteristic surface spatial frequencies. Images are presented with the axes ratio $x: y: z$ as $1: 1: 150$.

High-dose nitrogen ion implantation at the energy $E=50 \mathrm{keV}$ into epitaxial $\mathrm{Y}_{2.95} \mathrm{La}_{0.05} \mathrm{Fe}_{5} \mathrm{O}_{12}$ films did not lead to significant changes in the surface nanostructure. There is a slight smoothing of the film surface relief due to the fact that atoms on the ledges have the lowest binding energy and are effectively sputtered, that is numerically confirmed by changes in relief amplitude parameters.

\subsection{Structural changes under the influence of ion implantation}

Processes of interaction of nitrogen ions with the atoms in $\mathrm{Y}_{2.95} \mathrm{La}_{0.05} \mathrm{Fe}_{5} \mathrm{O}_{12}$ crystal lattice during high-dose ion implantation were investigated using the theory of elastic collisions with the software SRIM - 2008 [11]. It was assumed that creation of defects happened only as a result of transfer of the $\mathrm{N}^{+}$ion energy to the target subsystem at elastic collisions. Subthreshold effects structural disorder at the inelastic processes of excitation and electron shells ionization were not taken into account. For YIG single crystal, the threshold displacement energy $E_{d}$ according to [12] is: for oxygen ions $\approx 30 \mathrm{eV}$, for ions $\mathrm{Fe}^{3+}-56 \mathrm{eV}$ and for $\mathrm{Y}^{3+}-66 \mathrm{eV}$.

The electron energy loss is $67.2 \%(28.5 \mathrm{eV} / \AA)$ and nuclear energy loss is $32.8 \%(13.9 \mathrm{eV} / \AA)$ at the implantation energy $E=50 \mathrm{keV}$. In many cases, the energy transferred by ion into the nuclear matrix subsystem along the length of the track reaches values that are necessary to develop secondary displacement cascade.

Appearance of a large number of radiation defects is caused by nitrogen ions embodied in the lattice garnet films, and oxygen is distracted from the surface of the films in $60 \%$ of all cases, iron - in $28 \%$, yttrium - in $13 \%$, and lanthanum - in $<1 \%$.

\subsection{Magnetic force microscopy}

Magnetic force microscopy (MFM) of the samples was carried out to study the effect of implantation on the magnetic properties, in particular, distribution of magnetic domains in films. MFM-microscopy images were obtained for samples of different thickness and with various irradiation ion doses (Figs 2 and 4). The experiment was made using a scanning probe microscope NanoScope IIIa Dimension 3000. The resonance method of MFM-imaging is based on that the stiffness coefficient $c_{0}$ of an elastic oscillation system (console) is changed by the interaction of magnetic probe with a scattering fields created by domain structure (DS), and is equal to [13]

$c=c_{0}-\partial F_{z} / \partial z$.

Here, $z$ is the coordinate measured from the scanned surface, and $F_{z}-z$-component of the interaction force (usually it's dominant), which is [14]

$$
F_{z}=\int_{V}\left(M_{x} \frac{\partial H_{x}}{\partial z}+M_{y} \frac{\partial H_{y}}{\partial z}+M_{z} \frac{\partial H_{z}}{\partial z}\right) d V^{\prime},
$$

where $M_{i}$ are the magnetization components of the probe, $H_{i}$ - magnetic scattering field components of DS, and integration is made over the probed magnetic layer $V$.

The accuracy in quantitative calculations of the interaction force $F_{z}$ depends on geometry of the probe and type of magnetic coating. To do it in a precise manner is very difficult even for the static scan mode. However, to visualize distribution of magnetization in DS, it is enough to take into account the fact that attraction $\left(\partial F_{z} / \partial z>0\right)$ makes the system more flexible, and repulsion $\left(\partial F_{z} / \partial z<0\right)$ - more strict. It means that the oscillation frequency depends on $\partial F_{z} / \partial z$ :

$$
\omega=\omega_{0} \sqrt{1-\frac{1}{c_{0}} \frac{\partial F_{z}}{\partial z}} \approx-\frac{1}{2 c_{0}} \frac{\partial F_{z}}{\partial z}
$$

where $\omega_{0}$ is the intrinsic resonant frequency of the elastic system.

\section{(C) 2013, V. Lashkaryov Institute of Semiconductor Physics, National Academy of Sciences of Ukraine}




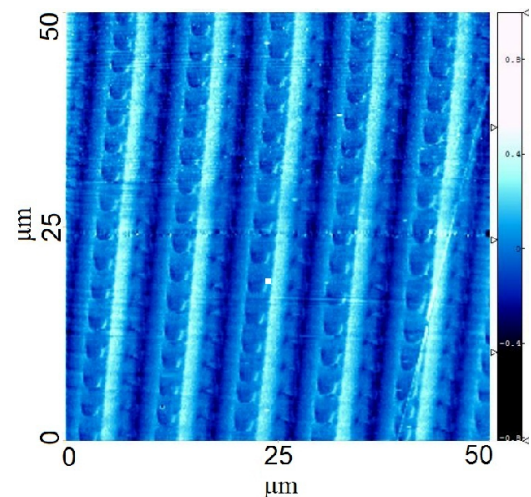

a)

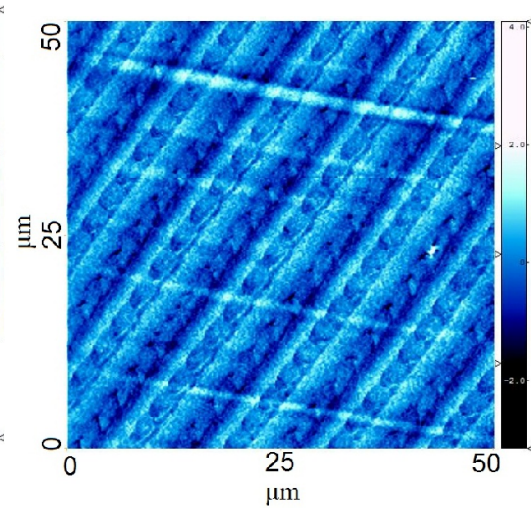

b)

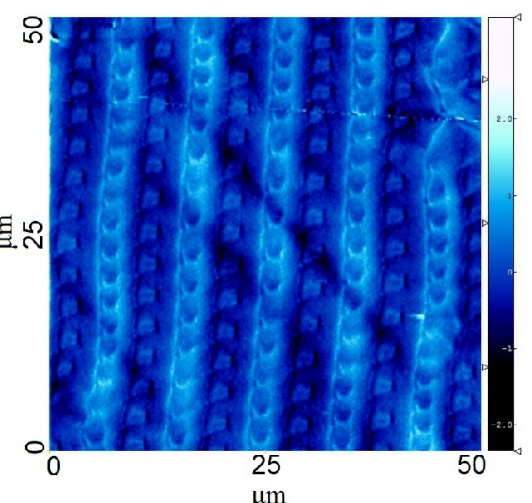

c)

Fig. 2. MFM maps of scattering field gradient distribution of surface layers magnetic domains of YIG films: a) №1; b) №1a; c) №1b.

It should be noted that DS of ferrite-garnet films is very sensitive even to weak magnetic fields, so MFM probes were selected to provide practical absence of mutual influence with surface for these studies. The twopass MFM technique (lift mode) was used to eliminate the influence of relief. In the first pass, the probe recorded the profile of relief, and then returned to the starting point of line scan, was raised to a given height (in our measurements $100 \mathrm{~nm}$ ) and fulfilled the second pass, repeating the registered surface profile and keeping constant tip-sample distance. So, the magnetic field gradient was measured during the second pass, detecting shifts of MFM tip oscillations due to magnetic interaction.

Some data on the magnetic structure of ferritegarnet films will help us to explain the obtained images. Epitaxial ferrite-garnet films with orientation (111), depending on the value of uniaxial anisotropy constant $K_{u}$ and the saturation magnetization $M_{s}$, have two types of magnetic anisotropy:

- $K_{u} / 2 \pi M_{s}^{2}>>1-$ uniaxial anisotropy is higher than own garnet cubic anisotropy, and easy magnetization axis is directed along the normal to the film surface (111). These specifications have films with cylindrical magnetic domains (such as $(\mathrm{YSmLuCa})_{3}(\mathrm{FeGeSi})_{5} \mathrm{O}_{12}$ film);

- $K_{u} / 2 \pi M_{s}^{2}<<1-$ magnetization vector deviates at a small angle from the plane of the film owing to its own cubic anisotropy. Ones of films with such characteristics are $\mathrm{Y}_{3} \mathrm{Fe}_{5} \mathrm{O}_{12}$ ferrite-garnet films and La-substituted YIG.

In general, YIG and La:YIG films can be characterized by a mixed uniaxial and cubic magnetic anisotropy. Lanthanum doping this YIG is used to reduce the difference in lattice parameters of film and substrate and has practically no effect on magnetic properties of films. The domain structure in films with the thickness up to $36 \mu \mathrm{m}$ has the form of stripes that are due to the normal to film surface component of the magnetization, which creates magneto-optical contrast [15]. These stripes are oriented mainly in three directions [15-17] at every $120^{\circ}$ angle along the crystallographic directions [11 $],[1 \overline{2} 1]$ and [ $\overline{2} 11]$. If the thickness is larger than $36 \mu \mathrm{m}$, the domain structure becomes more complicated as a result of domain branching when entering free surface of the sample [15].

Fig. 2 shows the MFM-images for La:YIG films with the thickness $21.9 \mu \mathrm{m}$, where one can see the series of complex distinct parallel stripes with the same width of about $9 \mu \mathrm{m}$. The domain structure, presented in figure, is typical when branched domains enter free sample surface, which is observed in the case of thick films (formal reduction of the critical film thickness is also caused by the existence of significant heterogeneity of magnetic properties along the film thickness). Herewith, it should be noted that the MFM-image is formed by scattering fields and shows mainly the distribution of magnetization in the subsurface layer.

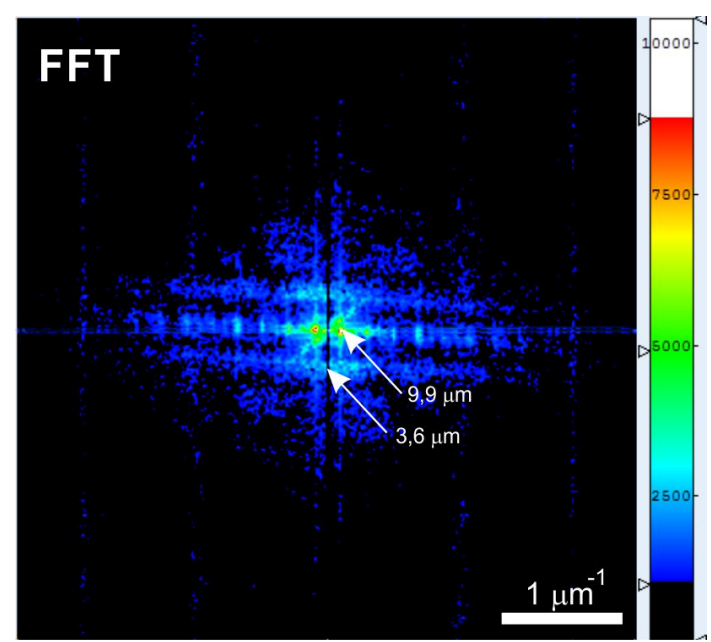

Fig. 3. The data of Fourier analysis of spatial frequencies of magnetic domains arrangement of the sample №1b. 


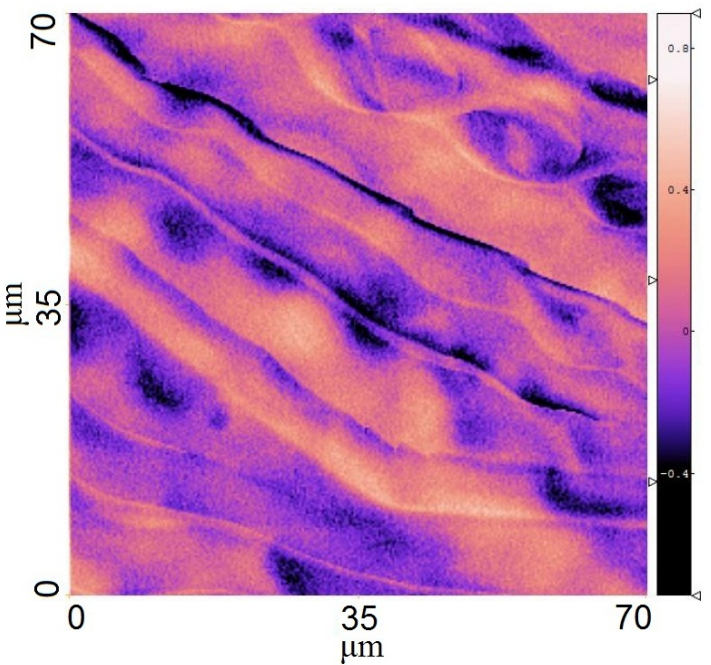

a)

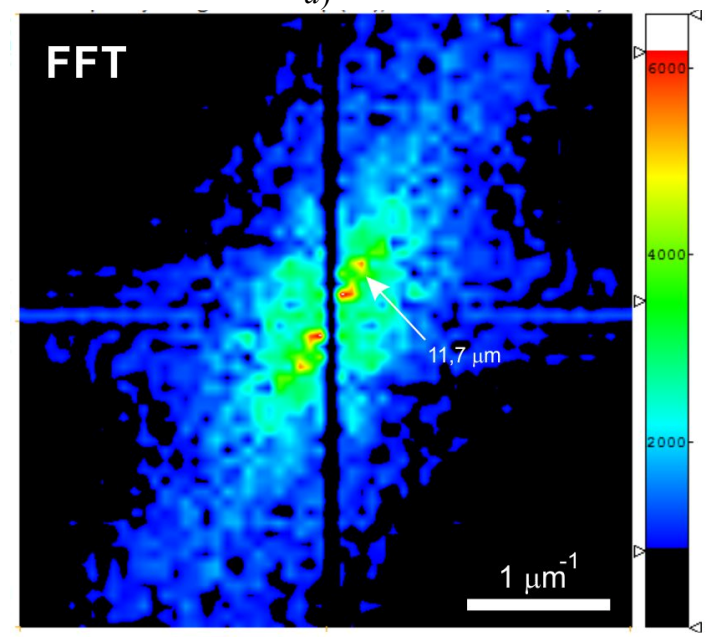

c)

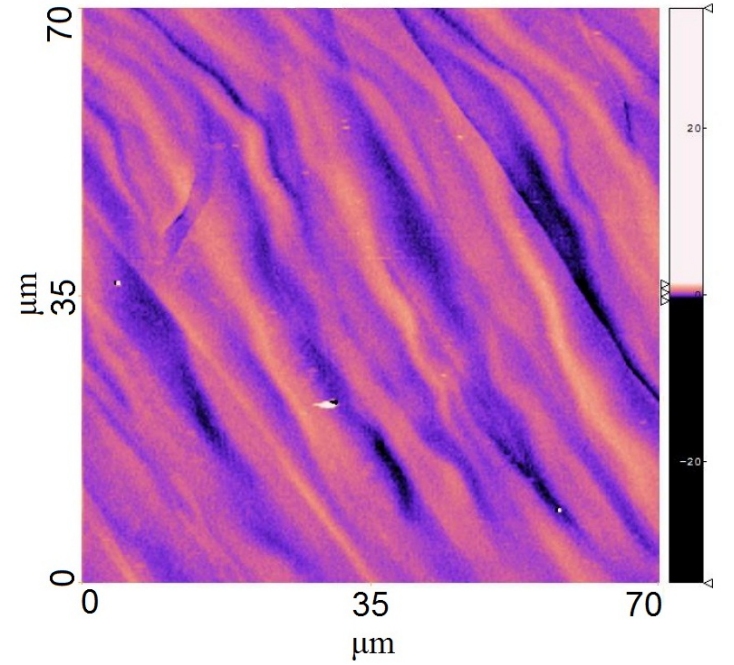

b)

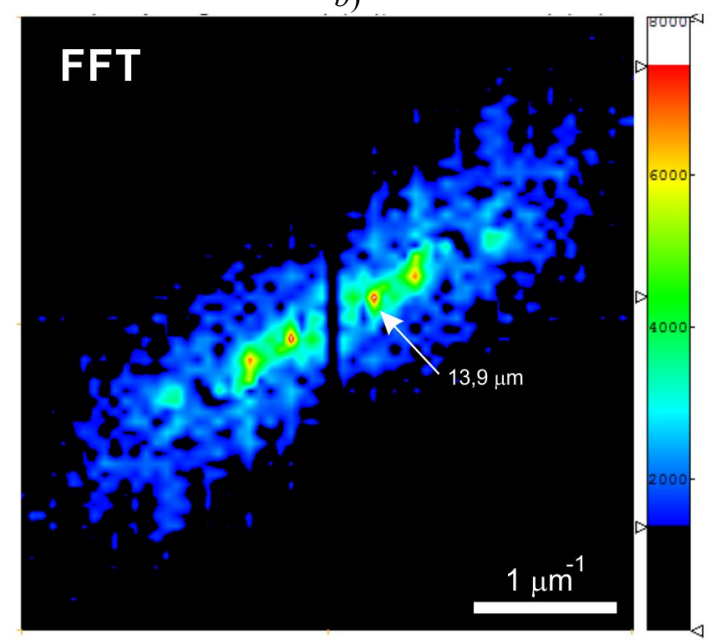

d)

Fig. 4. Magnetic force microscopy data of YIG films №2 (a) and №2a (b) and corresponding data of Fourier analysis of spatial frequencies $(c, d)$.

In our case, the subsurface layer of films with the thickness $21.9 \mu \mathrm{m}$, according to the results of structural analysis [18, 19], has a mosaic structure, moreover mosaic blocks are disoriented by the angle 111", the deformation of blocks is proportional to the square of the deviation angle of block surface, and the block reversals occur themselves in certain well-defined line along the sample surface. This mosaic layer leads to branching the main domains and formation of the subsurface ones [20], and possibly to the organization of a continuous layer of subsurface domains [21]. Domain structure ordering along certain direction is caused by violation of the equivalence of domain boundaries in various directions within the film plane due to the presence of anisotropy in the mosaic block reversals [18].

High-dose implantation with nitrogen ions leads to symmetrisation of ordered series of domains. Partially related series of subsurface domains on light and dark background with the dose of implantation close to
$5 \cdot 10^{18} \mathrm{~cm}^{-2}$ become clearly separated. The data of spatial frequencies analysis (Fig. 3) clearly indicate anisotropy and periodicity of magnetic domains spatial ordering with a characteristic frequency in mutually perpendicular directions 9.9 and $3.6 \mu \mathrm{m}$. Note that these periods do not correlate with periods of the surface relief. This is obviously related to amorphization and atomization of the surface layer, which can have a thickness up to $0.5 \mu \mathrm{m}[22]$ in YIG.

Herewith, this mosaic layer is much thicker, and the largest part of it remains on the film surface even after implantation, as evidenced by maintaining a complex domain structure, which is a result of heterogeneity in the film thickness of magnetic properties, and by the shape of reciprocal space maps $[18,19]$. Obviously, the presence of mosaic structure and surface layer, which is significantly dispersed and amorphized by means of high-dose ion implantation, leads to narrowing the FMR line more than twice.

\section{(C) 2013, V. Lashkaryov Institute of Semiconductor Physics, National Academy of Sciences of Ukraine}


MFM-images of films with the thickness $76.4 \mu \mathrm{m}$ in Fig. 4 are radically different from previous ones. Nonimplanted and implanted samples (Fig. 4) have domain magnetic stripes with an irregular thickness and show characteristic anisotropic frequency about $12 \ldots 14 \mu \mathrm{m}$ (see Figs $4 \mathrm{c}$ and $4 \mathrm{~d}$ ). This frequency coincides well with the characteristic spatial periods of thick films surface relief. However, a significant difference is the anisotropy of relief periods. Magnetic stripes of these samples are the special case of magnetic stripe domains that appeared as closed at the film surface and obviously can be referred to the stripe structures. The stripe structure is formed when perpendicular to the surface component of magnetization appears in the locked domains, and this component oscillates relatively to the film plane. The cause of the stripe structure appearance is a column microstructure formed during the growth of films and determines transverse to the surface anisotropy component, which is anisotropy of its shape. In homogeneous YIG films, the value of the critical thickness for appearance of stripe structures during isothermal epitaxial growth is not achieved, except of existence of significant heterogeneity of magnetic properties along the film thickness, which reduces the value of the critical film thickness and contributes to the emergence of subsurface domains [23, 24].

The film №2 with the thickness $76.4 \mu \mathrm{m}$ is almost uniform in the thickness and is clearly identified by X-ray structural data (rocking curves, reciprocal space maps) for the surface layer $[18,19]$ that was formed during film growth above fusion of solvent and is highly defective. The result of this crystal structure heterogeneity is the presence of magnetic properties that are heterogeneous along the film thickness. This leads to conditions that provide possibility for creation of stripe structures. Strong lateral heterogeneity of subsurface layer leads to violation of stripe periodicity. The film surface after implantation has a tendency of smoothing the nanorelief roughnesses according to AFM. The presence of defects in the crystal structure leads to appearance of irregularities and creation of magnetic domain structure, displayed in MFM-images as non-periodic ellipses and turbulences. Some surface defects disappeared, and domain structure, although it was still non-periodic, became more ordered after ionic implantation. The direction of stripes is obviously related to the presence of mechanical stresses in the film caused by cutting the sample in parts, and their width is different because of incomplete removing the subsurface transition layer by implantation.

\section{Conclusions}

It has been established that decrease in the FMR line width of La:YIG films, which is observed after highdose ion implantation, is accompanied by significant ordering of the structure of magnetic domains near the implanted films surface. These changes are caused by amorphization and atomization of surface layer, reduction of oxygen concentration, and thereafter increase of the part of magnetic ions $\mathrm{Fe}^{2+}$.
The highest dose of nitrogen ions is the best to use for making epitaxial YIG films as elements of highfrequency electronics, because these doses cause the highest narrowing the FMR line in the studied films.

\section{References}

1. A.G. Gurevich, G.A. Melkov, Magnetic Vibrations and Waves. Nauka, Moscow, 1994, in Russian.

2. H.L. Glass, Ferrite films for microwave devices // Proc. IEEE, 76(2), p. 64-72 (1988), in Russian.

3. A.M. Prokhorov, G.A. Smolensky, A.N. Ageev, Optical phenomena in thin film magnetic waveguides and their technical use // Uspekhi fiz. nauk, 143(1), p. 33-73 (1984), in Russian.

4. S.I. Yushchuk, Monocrystalline ferritegarnet films for microwave electronics // Technologia $i$ konstruirovanie $v$ elektronnoi apparature, 1, p. 3538 (1998), in Russian.

5. I.E. Dickstein, O.A. Maltsev, Ferromagnetic resonance and magneto-static waves in inhomogeneous deformed iron garnet films // Radiotekhnika i elektronika, 37(11), p. 2003-2009 (1992), in Russian.

6. M.R. Hamze, Ju.F. Maltsev, The degree of perfection of the ferrite-garnet films and its effect on the loss of MSV, in: Physics and Techn. of Magnetic Phenomena, Kuibyshev, p. 85-90, 1986 (in Russian).

7. S.I. Yushchuk, S.A. Yur'ev, P.S. Kostiuk, Cultivation and properties of monocrystalline films (Y,Sc) ${ }_{3} \mathrm{Fe}_{5} \mathrm{O}_{12}$ // Inorganic Materials, 33(7), p. 881-883 (1997), in Russian.

8. S.I. Yushchuk, V.O. Kotsyubinsky, S.O. Yur'ev, I.P. Yaremiy, Effect of annealing on the magnetic properties of ferrite-garnet films // Physics and Chemistry of Solid State, 2(4), p. 735-739 (2001), in Ukrainian.

9. V.V. Randoshkin, A.Ja. Chervonenkis, Applied Magnetooptics. Energoatomizdat, Moscow, 1990 (in Russian).

10. Roger L. Easton Jr., Fourier Methods in Imaging. New York, John Wiley \& Sons, Inc., 2010.

11. J.F. Ziegler, J.P. Biersack, U. Littmark, The Stopping and Range of Ions in Solids. Pergamon Press, New-York, 1985.

12. Ya.O. Dovgiy, V.I. Kityk, A.O. Matkovskiy et al., The quantum-mechanical approach to the formation of defect states in gadolinium gallium garnet // Fizika Tverdogo Tela, 34(4), p. 1078-1087 (1992), in Russian.

13. H. Hopster, H.P. Oepen, Magnetic Microscopy of Nanostructures. Springer, Berlin, 2005.

14. U. Hartmann, Magnetic force microscopy // Annu. Rev. Mater. Sci. 29, p. 53-87 (1999).

15. S.B. Ubizskiy, Epitaxial ferrite-garnet structures for magnetic field sensors // PhD thesis, National University “Lvivska Politechnika”, Lviv, 2001 (in Ukrainian). 
16. A.V. Vashkovsky, E.G. Lokk, V.I. Shcheglov, Effect of induced uniaxial anisotropy on the domain structure and phase transitions of iron garnet films // Fizika Tverdogo Tela, 41(11), p. 2034-2041 (1999), in Russian.

17. V. Zavislyak, V.P. Sohatsky, M.A. Popov, G. Srinivasan, Electric-field-induced reorientation and flip in domain magnetization and light diffraction in an yttrium-iron-garnet/lead-zirconatetitanate bilayer // Phys. Rev. B, 87, 134417 (2013).

18. I.M. Fodchuk, I.I. Gutsuliak, R.A. Zaplitnyy, I.P. Yaremiy, A.Yu. Bonchyk, I.I. Syvorotka, The influence of high-dose irradiation by $\mathrm{N}^{+}$ions on the $\mathrm{Y}_{2,95} \mathrm{La}_{0,05} \mathrm{Fe}_{5} \mathrm{O}_{12}$ crystal structure // Metallofizika $i$ Noveishie Tekhnologii, 35(7), p. 999 (2013), in Russian.

19. I.M. Fodchuk, R.A. Zaplitnyy, I.I. Gutsuliak, I.P. Yaremiy, A.Yu. Bonchyk, G.V. Savytskiy, U.O. Tomyn, Investigation of the $\mathrm{Y}_{2.95} \mathrm{La}_{0.05} \mathrm{Fe}_{5} \mathrm{O}_{12}$ films properties after ion implantation // Physics and Chemistry of Solid State, 14(3), p. 547-552 (2013), in Ukrainian.
20. F.V. Lisowskiy, E.G. Mansvetova, M.P. Temiryazeva, A.G. Temiryazev, Study of branching domain structures in epitaxial films of yttrium iron garnet by the edge magnetic force microscopy // Pis'ma zhurnal eksperiment. teoret. fiziki, 96(9), p. 665-669 (2012), in Russian.

21. E.G. Lokk, M.P. Temiryazeva, V.I. Scheglov, Domain structure in magnetic films with saturation magnetization higher then anisotropy field // Proc. XXI Intern. Conf. in New Magnetism and Magnetic Materials, Moscow, p. 59-61, 2009 (in Russian).

22. S.I. Yushchuk, The layered structure of epitaxial films of yttrium iron garnet // Zhurnal Tekhnich. Fiziki, 69(12), p. 62-64 (1999), in Russian.

23. B.N. Filippov, A.P. Tankeev, Dynamic Effects in Ferromagnetics with Domain Structure. Nauka, Moscow, 1987 (in Russian).

24. B.N. Filippov, G.A. Shmatov, On the stability of near-surface magnetic domains in heterogeneous films // Fizika Metallov Metallovedenie, 61(6), p. 1094-1102 (1986), in Russian. 